\title{
Extracellular microRNAs in follicular fluids: implication for reproductive diseases
}

\author{
Zihui Wang ${ }^{1}$, Yanchufei Zhang ${ }^{1}$, Anyong Yang ${ }^{1}$, Yuxuan Ren ${ }^{1}$, Qipeng Zhang ${ }^{1}$, Peng Wang ${ }^{2}$ \\ ${ }^{1}$ Nanjing Drum Tower Hospital Center of Molecular Diagnostic and Therapy, Institute for Brain Sciences, State Key Laboratory of Pharmaceutical \\ Biotechnology, Jiangsu Engineering Research Center for MicroRNA Biology and Biotechnology, NJU Advanced Institute of Life Sciences (NAILS), \\ NJU Institute of AI Biomedicine and Biotechnology, Institute for Brain Sciences, School of Life Sciences, Nanjing University, Nanjing, China; \\ ${ }^{2}$ Medical Center for Human Reproduction, Beijing Chao-Yang Hospital, Capital Medical University, Beijing, China \\ Contributions: (I) Conception and design: Q Zhang, P Wang; (II) Administrative support: Q Zhang, P Wang; (III) Provision of study materials or \\ patients: None; (IV) Collection and assembly of data: None; (V) Data analysis and interpretation: None; (VI) Manuscript writing: All authors; \\ (VII) Final approval of manuscript: All authors. \\ Correspondence to: Qipeng Zhang. Nanjing Drum Tower Hospital Center of Molecular Diagnostic and Therapy, Institute for Brain Sciences, State \\ Key Laboratory of Pharmaceutical Biotechnology, Jiangsu Engineering Research Center for MicroRNA Biology and Biotechnology, NJU Advanced \\ Institute of Life Sciences (NAILS), NJU Institute of AI Biomedicine and Biotechnology, Institute for Brain Sciences, School of Life Sciences, \\ Nanjing University, Nanjing, China. Email: qpzhang@nju.edu.cn; Peng Wang. Medical Center for Human Reproduction, Beijing Chao-Yang \\ Hospital, Capital Medical University, Beijing, China. Email: wangpengdoc@hotmail.com.
}

\begin{abstract}
MicroRNAs (miRNAs), a class of small non-coding RNAs, are important regulators on a post-transcriptional level. As a classical non-coding RNA, miRNAs are expressed in various tissue and are involved in many biological processes. More recently, increasing evidence has confirmed the existence of the secreted miRNAs in follicular fluid, which shed a light on the local intercellular communication. Interestingly, the miRNA profile of follicular fluids is different temporally, suggesting that miRNA secretion is finely controlled during times of development and aging. The secretion of miRNAs by somatic cells in the ovary follicle is an important resource of follicular fluid miRNAs. Comparing the miRNAs profile between follicular fluid and plasma could reveal critical miRNAs that come from circulation. The physiological functions of miRNAs in follicular fluid are believed to be a versatile message carrier for cell communications, however, due to the lack of cell-type-specific labeling methods, the route of information transmission remains elusive. It is well known that miRNA expression changes in different disease state, so it might be suitable as a biomarker. Further investigating the regulatory mechanisms mediated by these secreted miRNAs can help to understand the molecular mechanisms of oocyte maturation, early embryo development, and implantation. Therefore, this review summarizes the functions of extracellular follicular fluid miRNAs, and discusses recent progress on the potential of secreted miRNA as a biomarker in reproductive diseases.
\end{abstract}

Keywords: MicroRNA; follicular fluid; oocyte formation; cell communication; biomarker

Received: 11 December 2020; Accepted: 01 September 2021; Published: 30 September 2021.

doi: 10.21037/exrna-20-3

View this article at: https://dx.doi.org/10.21037/exrna-20-3

\section{Background}

MicroRNAs (miRNAs) are a group of small (usually, 18 to 25 nucleotides in length), non-coding RNAs that have important roles in controlling gene expression by binding to the targeted sites on mRNAs, most commonly in their 3'-untranslated region (3'-UTR). After being bound by
miRNA in the 3'-UTR site, the mRNA translation is suppressed or they undergo to a degradation (1). MiRNAs have a broad influence on gene expression, a single miRNA can target hundreds of mRNAs, which have one or multiple binding sites in its 3'-UTR, also a specific mRNA molecule could be influenced by several different miRNAs. In animal 
cells, a multi-protein RNA complex, named RNA induced silencing complex (RISC), is assembled by mature miRNAs and many proteins. Ago2 protein, which directly binds to miRNAs, is the core component of RISC $(2,3)$. It is estimated that about $30-60 \%$ of total proteins are influenced by miRNAs, therefore, it is not surprising that miRNAs play key roles in many different biological processes, such as cell proliferation, differentiation, migration, and apoptosis. Importantly, in the physiological or pathological process of various developmental stages or diseases such as cancer and degenerative diseases, the expression profiles of miRNAs are altered in a spatial and temporal pattern $(4,5)$.

Previous studies have demonstrated that miRNAs are also detectable outside cells; these miRNAs may be referred to as extracellular miRNAs. Extracellular miRNAs are found in various body fluids, for instance, in serum, plasma, nasal mucus, saliva, tear fluid, urine, seminal fluid, and follicular fluids. A multitude of research has shown that these extracellular miRNAs are dynamically altered in various physiological or pathological conditions, suggesting the potential to use them as biomarkers for different diseases. In addition, extracellular miRNAs are potential functional for their recipient cells, usually, they exist in extracellular vesicles, such as exosomes or shedding vesicles, who protect the miRNAs from the degradation of RNases and carry these functional nucleotides into the receipt cells. Secreted miRNAs mediate communication among the different cells. Given that secreted miRNAs mediate communication among different cells, investigating the molecular mechanisms could reveal insight into the disease pathogenesis and progression.

The recent identification of extracellular miRNAs in follicular fluids opens the door to various applications. As a daily by-product of controlled ovarian hyperstimulation and oocyte retrieval, the follicular fluids is an important body fluid subject. Studying the extracellular miRNAs in follicular fluids could provide a new aspect of research and a useful therapeutic site for many reproductive diseases. In this review, we pooled the latest research results of extracellular miRNAs in the follicular fluid and provided a system review.

\section{Development and maturation of ovarian follicle}

During development, the primordial follicles are formed when the flattened follicular (granulosa) cells surround the oogonia cells. These primordial follicles remain in the resting stage before being activated during development. Next, the oocytes are surrounded by cuboidal follicular (granulosa) cells in the preantral follicles. After stimulation by many growth factors (mainly FSH), granulosa proliferate and antrum begins to form, which is indicative of the secondary follicle stage. At the antral stage, follicles become gonadotropin-dependent and form large antral follicles, most of which undergo atresia, and few are selected for ovulation. An important feature of follicular formation is the development of dominant mature follicles. As the follicle develops, a follicle fluid-filled lumen gradually forms within the granular layer, while granulosa cells accumulate in the outer layer of this lumen and finally become cumulus around the oocyte (6) (Figure 1).

Follicular fluids played an important role in this complex process due to the possibility of information exchange. Follicular fluids consist of a compound of water, ions, proteins, lipids, and nucleic acids, etc. Based on previous studies, follicular fluids provide an important microenvironment for the development of the oocytes $(7,8)$. A detailed characterization of follicular fluid can provide critical information, which reflects the quality of oocytes and distinguishes the way of follicular differentiation and development (9). Different type cells secret biomolecules to the follicular fluid during the development of oocyte, and this paracrine ensures the maturation of the oocyte, coordinates the key stages in oocyte maturation, and makes the oocyte fully ready for fertilization (10). There are gap junctions between oocytes and cumulus cells (CCs), given that the follicular fluid provides a water environment inside the antrum, therefore, which supports the interaction between oocytes and other somatic cells (8).

\section{Profiles of secreted miRNA in follicular fluids}

In 2012, da Silveira et al. first identified secreted miRNAs in follicular fluid of equine ovary. Due to its bigger size, the follicular fluid could be easily drawn, both the fluid and the cells in the equine follicle are collected (11). The authors found that the miRNAs in follicular fluid were in microvesicles or exosomes; these miRNA-containing vesicles could be uptaken by granulosa cells or cumulus cells, which suggests the microRNAs horizontal transfer between different cells in the follicular fluid. In 2013, Sang et al. reported miRNAs profiles in human follicular fluid. First, they collected the microvesicles from fresh follicular fluids, and then they found more than 100 miRNAs $\left(\mathrm{C}_{\mathrm{T}}\right.$ $<37)$ existed in the microvesicles while there were equivalent kinds of miRNAs $\left(\mathrm{C}_{\mathrm{T}}<37\right)$ in the supernatant. Comparing the miRNAs profile of women with or without polycystic 


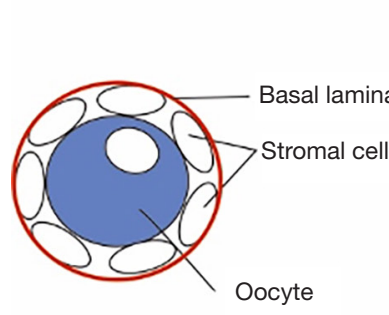

Primordial follicle

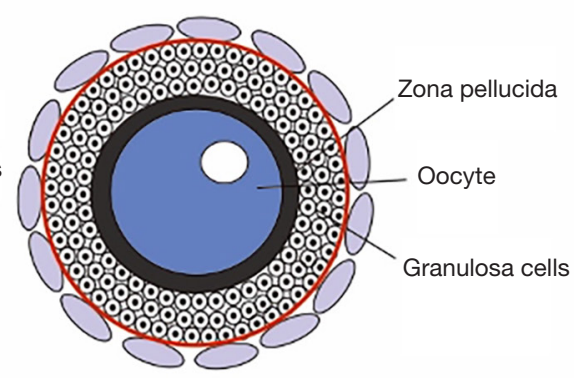

Secondary follicle

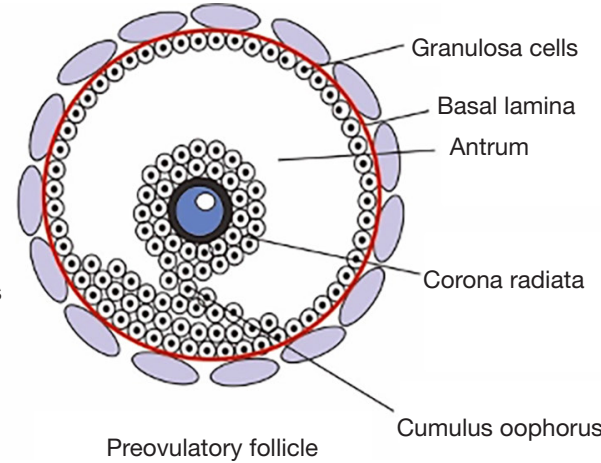

Preovulatory follicle

Figure 1 Development and maturation of ovarian follicle. The primordial follicles (PMFs) are formed during embryonic development. At this stage, the PMF oocyte is staying at its first prophase of meiosis, while somatic pre-granulosa cells surround the oocyte and form a flattened layer (Left in the figure). The follicles will further reach the secondary pre-antral follicles, a stage that depends on bidirectional communication between the oocyte and the surrounding somatic cells (Middle in the figure). Usually, only one or two of the follicles, will achieve the preovulatory stage at each reproductive cycle, which is named as the dominant follicles, rest of the follicles, which also develop in the same reproductive cycle, go into atretic degeneration. The matured follicle is composed of oocyte, cumulus cells, and granulosa cells. There is follicular fluid in the antrum cavity.

ovary syndrome (PCOS), the authors found two miRNAs (miRNA-132 and miRNA-320) were lower with PCOSlinking changes in extracellular miRNA to reproductive diseases (9). After these two seminal studies, the miRNA profiling of extracellular miRNAs in follicular fluids began to rapidly emerge and expand to almost all foliar-related fields.

There are about 100-300 individual miRNAs present in follicular fluids out of the total 300-700 miRNAs which were screened. By using RT-quantitative PCR, The $\mathrm{C}_{\mathrm{T}}$ value of the highest concentration of miRNA is about 18 , while for most studies, the threshold of $\mathrm{C}_{\mathrm{T}}$ value for a low concentration of miRNA is 37 cycles. According to the standard curve, this may range from $\mathrm{pmol} / \mathrm{L}$ to $\mu \mathrm{mol} / \mathrm{L}$ in concentration. Given that they are distributed in vesicles, which are engulfed or merged with cell membranes, the local concentrations of miRNAs in subcellular compartments are higher than the above calculated averaged concentrations. The extracellular miRNAs in follicular fluids are fully potential functional after they entered the receipt cells. For example, the extracellular miRNAs in follicular fluids, such as miRNA-24, miRNA-132, miRNA-320, miRNA-520c-3p, and miRNA-222 were found to regulate estradiol secretion, while miR-24, miR-193b, and miRNA-483-5p were found to influence progesterone secretion (9).

\section{Origin of secreted miRNA in follicular fluids}

Notably, most of the miRNAs profiling studies identified the global miRNA profiles contained in vesicles from raw follicular fluids, instead of sampling the vesicles released by a specific cell type. Some studies have compared the miRNAs in microvesicles or exosomes extracted from follicular fluid and the miRNAs profile of surrounding granulosa and cumulus cells through miRNA expression profile analysis (11). In 2017, Andrade et al. screened and identified cell-specific and differentially expressed miRNAs from the bovine GCs and cumulus-oocyte complexes (COCs) (12). By quantitative RT-PCR. they discovered 326 miRNAs in GCs and COCs cells and 62 miRNAs existed in the EVs. In the same year, Battaglia et al. employed a high-throughput analysis to detect miRNAs in human oocytes and miRNAs in follicular fluid. Two hundred and sixty-seven miRNAs were identified in follicular fluid, while 176 miRNAs were expressed in oocytes. What's more, most of oocyte miRNAs were also detected in follicular fluids, only 9 miRNAs were believed to be oocyte-specific. MicroRNAs in follicular fluid and oocytes were then analyzed using bioinformatic methods to identify the possible biological processes and pathways regulated by their validated targets. There are many common pathways between the two compartments, some of which are specific to oocyte miRNAs. In addition, fortyone long non-coding RNAs have been found to interact with microRNAs in oocytes. These long-chain non-coding RNAs may be closely related to follicular development and have certain regulatory effects (13). The liquid of follicular 

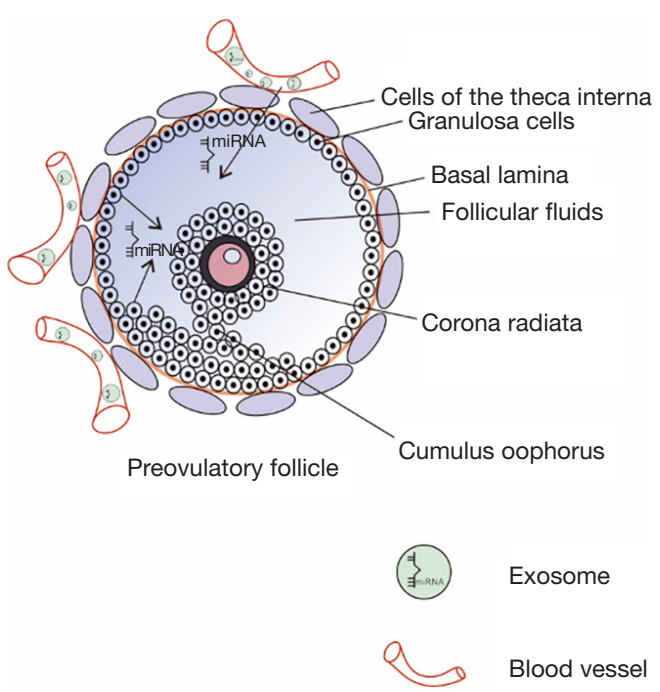

Figure 2 Origin of extracellular miRNA in follicular fluids and cell communications via miRNAs. Besides coming from circulation, both granulosa cells and cumulus cells can secrete miRNA into follicular fluids, there is no evidence showing that the oocyte could secrete miRNAs. While the secreted miRNA could be absorbed by the oocyte, granulosa cells, cumulus cells.

fluid is mainly composed of plasma since many plasma ingredients crossed the blood-follicle barrier via thecal capillaries. Follicular fluid also contains factors that are produced locally by follicular cells; the production of these factors varies with the reproductive state (14). In 2013, Murri et al. found miR-103 in both blood and follicular fluids (15). Thereafter, by comparing the miRNAs profile of FF and plasma from the same patients, Santonocito et al. found 37 miRNAs upregulated in human FF within the plasma (16). Interestingly, they found that miR-508$3 p$ seems to be a follicle-specific miRNA. Eight miRNAs (miR-10b, miR-29a, miR-99a, miR-125b, miR-132, miR202, miR-212, and miR-874) were expressed abundantly in granulose or cumulus cells in humans and mice. Nevertheless, it remains unknown if labeled miRNAs could be transported into follicular fluids by direct diffusion from vessels into the follicular fluids through circulation. Thus, it is just speculation whether miRNA in follicular fluids originate from the secretion by local cells or from the distal circulation transportation (Figure 2).

\section{Dynamic changes of follicular fluids miRNAs}

Since the miRNAs in follicular fluids are secreted by local reproductive cells or derived from circulation, the profiles of miRNA might experience a dynamic change through development and at physiological status. For example, aging is a key contributor to the beginning of the reproductive decline. Studies on the changes of follicular miRNA with age began with mares: different miRNAs were identified in exosomes in old versus young mare ovarian follicular fluid (11). This result indicates the extracellular miRNAs profiles may be a useful index for oocyte quality evaluation. Two years later, the same group of researchers further found that the difference of follicular fluid exosomal miRNAs in young and old mares was associated with expression changes of TGF- family members in granulosa cells (17). In the same year, Diez-Fraile et al. found that in humans, four microRNAs in follicular fluids including hsa-miR-215p, hsa-miR-134, hsa-miR-190b, and hsa-miR-99b-3p are differentially expressed in an age-related pattern (18). In another experiment, the mouse embryonic development is significantly affected after receiving miR-320 inhibitors (19). These findings extend the impact of aging on the ingredients of the follicular fluid microenvironment and suggest that extracellular miRNAs in follicular fluid can be used as sensitive biomarkers to reflect oocyte's quality.

Aging is a relative long-time course, studies have shown that the miRNA profiles are changed in oocyte maturation stage, for example, there are 13 differentially expressed miRNAs (two up and 11 down regulated) in the follicular fluid of metaphase II (MII) versus GV (germinal vesicle) oocytes (20). de Avila et al. found microRNA contents of small extracellular vesicles are modulated by the estrous cycle for the first time (21). Similar experiments were carried out, Sontakke et al. measured small (4-8 mm) or large $(12-17 \mathrm{~mm})$ bovine follicles and analyzed their miRNA profiles by qPCR validation (22). There were 17 and 57 sequences differentially expressed in large healthy follicles and small and large atresia follicles, respectively. Further studies confirmed that bovine miRNAs (miR144, miR-202, miR-451, miR-652, and miR-873) were up-regulated in healthy, large follicles compared to the miRNAs within small follicles. In large atresia follicles, three of the miRNAs (miR-144, miR-202, and miR-873) were also down-regulated. In follicles, the miRNAs are expressed mainly in mural granulocytes. In addition, systemic screening showed that miR-202, rather than other miRNAs, was expressed specifically in gonads. These results indicate that the miRNAs in follicular fluid might be well regulated and associated with different physiological statuses. 


\section{Cell communications mediated by extracellular miRNAs in follicular fluids}

As early as 2012, da Silveira $e t$ al. performed a series of in vitro and in vivo experiments: fluorescent dye PKH67 labeled microvesicles were added to the medium of cultured granulosa cells (11). There is a clear signal of PKH67 in cultured granulosa cells, which indicates that the microvesicles are capable to merge with cultured cells. In their in vivo experiment, PKH67 labeled microvesicles were injected back into the follicular fluid of the same dominant follicle where it was isolated. Again, the green signals are evident within the granulosa cells after injecting PKH67-labeled microvesicles to follicular fluid, as a negative control, there is no green signal in the group of injecting with PBS-incubated PKH67. This direct evidence shows that granulosa cells uptake fluorescent-labeled microvesicles. Co-incubation of bovine granulosa cells with labeled exosomes leads to an increase of miRNAs in these cells (23). Besides granulosa cells, cumulus cells also could uptake exosomes: cocultured with mesenchymal stem cells derived exosomes, cumulus cells receive the contents of these microRNAs. For example, the hsa-miR-323-3p, who promoted cell proliferation and suppressed apoptosis in receipt cumulus cells via suppressing the programmed cell death protein 4 (PDCD4) (24). Nevertheless, it remains up for debate whether extracellular vesicles in follicular fluid have an important role in cumulus expansion $(25,26)$, which is critical for ovulation of a fertilizable egg. Finally, it is found that the exosomes in follicular fluid play important roles during oocyte maturation to enhance oocyte function and protect it from stress (27). However, these studies use exosomes or microvesicles as a whole factor and do not check which specific exosome content is the effective factor of exosome function. Further work to identify miRNA candidates is needed. Genetic cell-specific labeling techniques may help to distinguish the different exosomes thus elucidating their specific roles.

\section{Possible physiological roles of follicular fluids miRNAs}

Since finding in follicular fluids, the follicular fluids miRNAs are supposed to play important roles in folliculogenesis (oocyte maturation), early embryo development, and implantation (28). First, the whole development of oocyte is accompanied by the formation of follicles, and then the maturation process of oocyte is incubated in follicular fluids, where there are extracellular miRNAs. In 2013, the first miRNAs profiles in microvesicles and the supernatant of human follicular fluid were reported. Bioinformatics analysis showed that the most highly expressed miRNAs target genes were related to reproductive, endocrine, and metabolic processes. Results indicate that miR-132, miR-320, miR-520c-3p, miR-24, and miR-222 regulate estradiol concentrations and that $\mathrm{miR}-24, \mathrm{miR}-193 \mathrm{~b}$, and $\mathrm{miR}-483-5 \mathrm{p}$ regulate progesterone concentrations (9). In 2014, Yin et al. found injection of miR-320 into the ovaries of mice partially promoted the production of testosterone and progesterone but inhibited estradiol release in vivo. Transfecting with miR-320 mimics significantly decelerated the proliferation of GCs in a dose-dependent manner, whereas the miR320 inhibitors increased cell proliferation (29). These studies indicate that the follicular fluid miRNAs regulate steroidogenesis. Although there are many miRNAs are reported to be involved in follicle development, no specific, essential miRNAs for oocyte maturation have been identified. Advanced gene-editing techniques to specifically knocking-out one or several miRNAs should be employed to decipher their role in folliculogenesis. In the follicular fluids of women with oocytes that failed to fertilize in vitro, the miR-92a and miR-130b are higher than healthy women (30). This suggests that miR-92a and miR-130b could be good candidates for genetic manipulations to test their role in oocyte maturation. Secondly, studies show that many follicular fluids miRNAs are indicative or correlated with early embryo development and implantation, which is critical for IVF outcomes. Feng et al. reported that higher miR-320 in human follicular fluid is indicative of high-quality oocytes which could achieve more than 7 cells through cleavage, while knockdown this miRNA significantly weakened the developmental potential of MII oocytes (19). In addition to the extracellular vesicles in follicular fluid contains miRNAs, the extracellular vesicles of oviduct origin also have been found to be capable of carrying miRNAs (31). In fact, as a key female reproductive organ, the oviduct receives the ovulated oocytes, and the fertilization, early embryo development all occurs in the oviduct. There should be some follicular fluids that are pooled in the oviduct and become a part of oviduct fluid. In vitro study showed that the extracellular vesicles secreted by bovine oviduct epithelial cell oviductal fluids could improve the developmental capacity of bovine zygotes and the quality of embryos produced in vitro (32). Therefore, both the extracellular miRNAs in follicular fluids and 
oviductal fluids could play vital roles in normal reproductive processes. Of noteworthy, current experimental evidence still only support that the extracellular miRNAs are associative and descriptive for the conclusion that miRNAs have above different biological functions. Further studies are still needed to elucidate the causal roles of miRNAs.

\section{Disease related chances of miRNAs in follicular fluids}

In 2013, Sang et al. demonstrated the existence of miRNAs in human follicular fluids and their use of bioinformatics analysis successfully revealed the role of miRNAs in targeting essential genes in metabolic pathways. Bioinformatics analysis found that 12 highly expressed miRNAs mainly target the genes involved in various biological processes, including folliculogenesis, metabolism, and immune responses (9). Interestingly, ovulatory dysfunction increased insulin resistance (IR), an elevated free androgen index (FAI), and inflammation are hallmarks of PCOS. They compared 22 controls and 22 PCOS patients found a distinctly higher serum concentration of luteinizing hormone and testosterone in PCOS patients. By measuring the expression level of several miRNAs, they also found the association between the miRNAs (miRNA-132 and miRNA-320) in the follicular fluids and PCOS. In 2016, Sørensen et al. found that the levels of miR-24-3p, miR-29a, miR-151-3p, and miR-574-3p in PCOS women were decreased compared with the controls (33). In 2017, Naji et al. found the differential expressions of miR-93 and miR-21 in GCs and follicular fluids of PCOS associated with different phenotypes (34). And in the same year, they also determined relative expressions of miR-15a, miR-145, and miR-182 in granulosa-lutein cells (GLCs), follicular fluids, and serum of PCOS patients. Finally, there was no difference in the expression level of miR-15a and miR145 in follicular fluids but miR-182 in follicular fluids are significantly up-regulated in PCOS patients (35). In 2019, Butler et al. recruited 30 normal women and 29 PCOS women, and their expression levels of miRNA were detected. Of the 176 miRNAs recorded, 29 miRNAs are significantly altered between normal women and women with PCOS. The Ingenious pathway assessment revealed that 12 miRNAs were associated with significant changes in reproductive pathways, 12 miRNAs are associated with inflammatory pathways, and 6 miRNAs are associated with benign pelvic diseases. The miRNAs in the follicular fluids between PCOS and normal control women are analyzed using the Ingenuity Pathway Analysis, and it was found that the differences were related to age, FAI, inflammation, and adrenal medullary hormone (AMH) in PCOS, and with BMI, fertilization rate (3 miRNAs), insulin resistance (36). In conclusion, the previous studies provide evidence that several miRNAs expression profiles in follicular fluids are altered in PCOS and indicate that specific follicular fluids miRNAs are associated with phenotypical traits of PCOS. An altered miRNA profile holds the potential for new methods of PCOS patient stratification and may be useful to explain the heterogeneous nature found within PCOS women. In addition to PCOS, there are some reproductive diseases that are associated with numerous miRNAs in human follicular fluids. Li et al. found that compared with controls, the distinction between patients with endometriosis and patients without endometriosis can be made by the downregulation of miR-451 in follicular fluid samples from patients with endometriosis. Downregulation of miR-451 in mouse and human oocytes can affect preimplantation embryogenesis by inhibiting the Wnt signaling pathway (37). WNT proteins are released extracellular signaling molecules that activate the $G$ proteincoupled receptors Frizzled (Fz). Studies have shown that the expression of WNTs and Fz occurs at specific stages of follicle growth and luteinization, and has important effects on follicle growth and development (38). As early as 2012, Conti et al. had shown that four of the upregulated miRNAs (miR-125b, miR-134, miR-202, miR-323-3p, and miR365) regulate WNT, MAPK, ErbB, and TGF $\beta$ signaling pathways by GO and Pathway analysis. Furthermore, it has been demonstrated that these signaling pathways play an essential role in follicular development, meiotic resumption, and subsequent ovulation (39). In order to make a clearer presentation, we have summarized related miRNAs in Table 1.

\section{Follicular fluids miRNAs as a potential disease biomarker}

Ovary is a vital place for the storage, maturation, and ovulation of oocytes. In the ovary, miRNAs execute important functions for coordinating the gene expression network. Recently, the detection of extracellular miRNAs in ovarian fluid, serum/plasma, and other body fluids have extended the traditional research scope in biomarkers discovery field (49). the extracellular miRNAs shuttle between somatic cells and the oocyte in follicular fluid, which bring controlling information to recipient cells. As 
Table 1 List of follicular fluids microRNAs in diseases

\begin{tabular}{|c|c|c|c|}
\hline Detected in tissue/cell & MicroRNA & Reported function(s) & References \\
\hline Follicular fluid & $\operatorname{miR}-382-5 p$ & Correlated with age and free androgen index (FAl) & (36) \\
\hline Follicular fluid & miR-93-3p & Correlated with C-reactive protein (CRP) & $(34,36)$ \\
\hline Follicular fluid & $\begin{array}{l}\operatorname{miR}-127-3 p, \operatorname{miR}-382-5 p \\
\operatorname{miR}-425-3 p\end{array}$ & Correlated with the fertilization rate & (36) \\
\hline Follicular fluid & $\operatorname{miR}-381-3 p$ & Correlated with FAI & (36) \\
\hline Follicular fluid & $\begin{array}{l}\text { miR-320, miR-520c-3p, } \\
\text { miR-24, miR-222 }\end{array}$ & regulate estradiol concentrations & (9) \\
\hline Follicular fluid & $\begin{array}{l}\text { miR-24, miR-193b, } \\
\text { miR-483-5p }\end{array}$ & Regulate progesterone concentrations & (9) \\
\hline Follicular fluid & miR-151 & $\begin{array}{l}\text { Negatively correlated with serum total and } \\
\text { free testosterone }\end{array}$ & (33) \\
\hline Follicular fluid & $\operatorname{miR}-451$ & $\begin{array}{l}\text { Affected pre-implantation embryogenesis by suppressing } \\
\text { the Wnt signalling pathway }\end{array}$ & (37) \\
\hline Follicular fluid & miR-518 & $\begin{array}{l}\text { Positively correlated with total and free testosterone and } \\
\text { androstenedione in PCOS } \\
\text { patients }\end{array}$ & (33) \\
\hline Granulosa cells & miR-93 and miR-21 & $\begin{array}{l}\text { Correlated with follicle development and adipogenic } \\
\text { differentiation }\end{array}$ & (34) \\
\hline Follicular fluid & miR-9 & Inhibits testosterone release & $(42,44)$ \\
\hline \multicolumn{4}{|l|}{ Granulosa cells } \\
\hline $\begin{array}{l}\text { Follicular fluid } \\
\text { Granulosa cells }\end{array}$ & $\operatorname{miR}-18 b$ & $\begin{array}{l}\text { Promotes progesterone release Inhibits testosterone and } \\
\text { estradiol release }\end{array}$ & $(42,44)$ \\
\hline $\begin{array}{l}\text { Follicular fluid } \\
\text { Granulosa cells }\end{array}$ & miR-132 & $\begin{array}{l}\text { Increases estradiol secretion Reduces } \\
\text { progesterone and testosterone release }\end{array}$ & $(9,42,45)$ \\
\hline $\begin{array}{l}\text { Follicular fluid } \\
\text { Granulosa cells }\end{array}$ & miR-383 & $\begin{array}{l}\text { Enhances the release of estradiol from GCs by } \\
\text { CYP19A1 }\end{array}$ & $(29,44,46)$ \\
\hline Follicular fluid & miR-224 & Induces GCs proliferation & $(47)$ \\
\hline Granulosa cells & & & \\
\hline
\end{tabular}

Table 1 (continued) 
Table 1 (continued)

\begin{tabular}{|c|c|c|c|}
\hline Detected in tissue/cell & MicroRNA & Reported function(s) & References \\
\hline \multicolumn{4}{|l|}{ Granulosa cells } \\
\hline Serum Plasma & miR-29a-3p & Associated with type 2 diabetes, insulin resistance & (33) \\
\hline \multicolumn{4}{|l|}{ Follicular fluid } \\
\hline Whole blood & $\mathrm{miR}-27 \mathrm{~b}$ & Positively correlated with testosterone & (15) \\
\hline Whole blood & $\mathrm{miR}-103$ & Promotes progesterone release Inhibits estradiol release & $(15,42)$ \\
\hline
\end{tabular}

non-coding RNAs, secreted miRNA put a fine-tuning effect on the gene expression $(50,51)$. Due to the relative stability in the extracellular environment against RNase activity, high or low $\mathrm{pH}$, and/or high temperature, miRNAs have been becoming a potential biomarker for oocyte and embryo quality in assisted reproduction therapy $(52,53)$. Up to date, there are thousands kinds of miRNAs recorded in miRbase, which means that plenty of miRNAs could be served as good biomarkers for different diseases (54). Specifically, the classification of extracellular miRNA expression patterns in follicular fluid can provide a reference data pool for assessing the different components of the ovary (16). Lastly, previous studies have shown that miRNAs could be an important role in the regulation of some pathways such as Wnt, MAPK, Erbb, insulin, neurotrophin signaling, which is critical signaling pathways in biological processes by which fetal ovarian development and adult ovarian function such as follicular maturation, steroidogenesis, and luteogenesis (55-57). Therefore, follicular fluids miRNAs could represent potential noninvasive molecular biomarkers for reproductive diseases such as PCOS, premature ovarian failure $(\mathrm{POF})$, and even ovarian cancers $(52,58,59)$.

\section{Conclusion}

Recent findings highlight that miRNAs can regulate gene expression at the post-transcription level and participate in a variety of biological development processes. In this review, we discuss the structure and developmental process of follicular fluid as well as the miRNAs profiles in follicular fluids. We propose a possible conjecture about the origin, the dynamic changes, and possible cell-to-cell communication roles of extracellular miRNAs in follicular fluids. Moreover, we summed up disease-related miRNAs and the possibility of employing miRNAs as a biomarker. And this review is intended to provide new ideas to help improve the development of new clinical diagnostic and therapeutic platforms. For example, using the RNAseq technique, one could simultaneously analyze the expression of miRNA in follicular fluids and mRNA in follicle cells. This would provide comprehensive molecular information on the roles of follicular fluid miRNAs in physiological and pathological states.

\section{Acknowledgments}

We would like to thank Samantha Howard (Tufts University School of Medicine) for her help in polishing the language of our paper.

Funding: This work was supported by grants from the National Natural Science Foundation of China (81871134 to Peng Wang, 31100777 and 81170309 to Qipeng Zhang) and the Fundamental Research Funds for the Central Universities (020814380119 and 020814380077 to Qipeng Zhang).

\section{Footnote}

Conflicts of Interest: All authors have completed the ICMJE uniform disclosure form (available at https://dx.doi. org/10.21037/exrna-20-3). The authors have no conflicts of interest to declare. 
Ethical Statement: The authors are accountable for all aspects of the work in ensuring that questions related to the accuracy or integrity of any part of the work are appropriately investigated and resolved.

Open Access Statement: This is an Open Access article distributed in accordance with the Creative Commons Attribution-NonCommercial-NoDerivs 4.0 International License (CC BY-NC-ND 4.0), which permits the noncommercial replication and distribution of the article with the strict proviso that no changes or edits are made and the original work is properly cited (including links to both the formal publication through the relevant DOI and the license). See: https://creativecommons.org/licenses/by-nc-nd/4.0/.

\section{References}

1. Bartel DP. MicroRNAs: genomics, biogenesis, mechanism, and function. Cell 2004;116:281-97.

2. Diederichs $S$, Haber DA. Dual role for argonautes in microRNA processing and posttranscriptional regulation of microRNA expression. Cell 2007;131:1097-108.

3. Meister G, Landthaler M, Patkaniowska A, et al. Human Argonaute2 mediates RNA cleavage targeted by miRNAs and siRNAs. Mol Cell 2004;15:185-97.

4. Cortez MA, Bueso-Ramos C, Ferdin J, et al. MicroRNAs in body fluids--the mix of hormones and biomarkers. Nat Rev Clin Oncol 2011;8:467-77.

5. Croce CM. Causes and consequences of microRNA dysregulation in cancer. Nat Rev Genet 2009;10:704-14.

6. Edson MA, Nagaraja AK, Matzuk MM. The mammalian ovary from genesis to revelation. Endocr Rev 2009;30:624-712.

7. Revelli A, Delle Piane L, Casano S, et al. Follicular fluid content and oocyte quality: from single biochemical markers to metabolomics. Reprod Biol Endocrinol 2009;7:40.

8. Rodgers RJ, Irving-Rodgers HF. Formation of the ovarian follicular antrum and follicular fluid. Biol Reprod 2010;82:1021-9.

9. Sang $\mathrm{Q}$, Yao $\mathrm{Z}$, Wang $\mathrm{H}$, et al. Identification of microRNAs in human follicular fluid: characterization of microRNAs that govern steroidogenesis in vitro and are associated with polycystic ovary syndrome in vivo. J Clin Endocrinol Metab 2013;98:3068-79.

10. Russell DL, Robker RL. Molecular mechanisms of ovulation: co-ordination through the cumulus complex. Hum Reprod Update 2007;13:289-312.
11. da Silveira JC, Veeramachaneni DN, Winger QA, et al. Cell-secreted vesicles in equine ovarian follicular fluid contain miRNAs and proteins: a possible new form of cell communication within the ovarian follicle. Biol Reprod 2012;86:71.

12. Andrade GM, Meirelles FV, Perecin F, et al. Cellular and extracellular vesicular origins of miRNAs within the bovine ovarian follicle. Reprod Domest Anim 2017;52:1036-45.

13. Battaglia $\mathrm{R}$, Vento ME, Borzì $\mathrm{P}$, et al. Non-coding RNAs in the Ovarian Follicle. Front Genet 2017;8:57.

14. Fahiminiya S, Gérard N. Follicular fluid in mammals. Gynecol Obstet Fertil 2010;38:402-4.

15. Murri $M$, Insenser $M$, Fernández-Durán E, et al. Effects of polycystic ovary syndrome (PCOS), sex hormones, and obesity on circulating miRNA-21, miRNA-27b, miRNA-103, and miRNA-155 expression. J Clin Endocrinol Metab 2013;98:E1835-44.

16. Santonocito M, Vento M, Guglielmino MR, et al. Molecular characterization of exosomes and their microRNA cargo in human follicular fluid: bioinformatic analysis reveals that exosomal microRNAs control pathways involved in follicular maturation. Fertil Steril 2014;102:1751-61.e1.

17. da Silveira JC, Winger QA, Bouma GJ, et al. Effects of age on follicular fluid exosomal microRNAs and granulosa cell transforming growth factor- $\beta$ signalling during follicle development in the mare. Reprod Fertil Dev 2015;27:897-905.

18. Diez-Fraile A, Lammens T, Tilleman K, et al. Ageassociated differential microRNA levels in human follicular fluid reveal pathways potentially determining fertility and success of in vitro fertilization. Hum Fertil (Camb) 2014;17:90-8.

19. Feng R, Sang Q, Zhu Y, et al. MiRNA-320 in the human follicular fluid is associated with embryo quality in vivo and affects mouse embryonic development in vitro. Sci Rep 2015;5:8689.

20. Moreno JM, Núñez MJ, Quiñonero A, et al. Follicular fluid and mural granulosa cells microRNA profiles vary in in vitro fertilization patients depending on their age and oocyte maturation stage. Fertil Steril 2015;104:1037-1046.e1.

21. de Ávila ACFCM, Bridi A, Andrade GM, et al. Estrous cycle impacts microRNA content in extracellular vesicles that modulate bovine cumulus cell transcripts during in vitro maturation†. Biol Reprod 2020;102:362-75.

22. Sontakke SD, Mohammed BT, McNeilly AS, et al. Characterization of microRNAs differentially expressed 
during bovine follicle development. Reproduction 2014;148:271-83.

23. Sohel MM, Hoelker M, Noferesti SS, et al. Exosomal and Non-Exosomal Transport of Extra-Cellular microRNAs in Follicular Fluid: Implications for Bovine Oocyte Developmental Competence. PLoS One 2013;8:e78505.

24. Zhao Y, Tao M, Wei M, et al. Mesenchymal stem cells derived exosomal miR-323-3p promotes proliferation and inhibits apoptosis of cumulus cells in polycystic ovary syndrome (PCOS). Artif Cells Nanomed Biotechnol 2019;47:3804-13.

25. Hung WT, Hong X, Christenson LK, et al. Extracellular Vesicles from Bovine Follicular Fluid Support Cumulus Expansion. Biol Reprod 2015;93:117.

26. Matsuno Y, Onuma A, Fujioka YA, et al. Effects of exosome-like vesicles on cumulus expansion in pigs in vitro. J Reprod Dev 2017;63:51-8.

27. Rodrigues TA, Tuna KM, Alli AA, et al. Follicular fluid exosomes act on the bovine oocyte to improve oocyte competence to support development and survival to heat shock. Reprod Fertil Dev 2019;31:888-97.

28. Salilew-Wondim D, Gebremedhn S, Hoelker M, et al. The Role of MicroRNAs in Mammalian Fertility: From Gametogenesis to Embryo Implantation. Int J Mol Sci 2020;21:585.

29. Yin $M$, Wang $X$, Yao G, et al. Transactivation of micrornA-320 by microRNA-383 regulates granulosa cell functions by targeting E2F1 and SF-1 proteins. J Biol Chem 2014;289:18239-57.

30. Martinez RM, Liang L, Racowsky C, et al. Extracellular microRNAs profile in human follicular fluid and IVF outcomes. Sci Rep 2018;8:17036.

31. Almiñana C, Tsikis G, Labas V, et al. Deciphering the oviductal extracellular vesicles content across the estrous cycle: implications for the gametes-oviduct interactions and the environment of the potential embryo. BMC Genomics 2018;19:622.

32. Lopera-Vásquez R, Hamdi M, Fernandez-Fuertes B, et al. Extracellular Vesicles from BOEC in In Vitro Embryo Development and Quality. PLoS One 2016;11:e0148083.

33. Sørensen AE, Wissing ML, Englund AL, et al. MicroRNA Species in Follicular Fluid Associating With Polycystic Ovary Syndrome and Related Intermediary Phenotypes. J Clin Endocrinol Metab 2016;101:1579-89.

34. Naji M, Aleyasin A, Nekoonam S, et al. Differential Expression of miR-93 and miR-21 in Granulosa Cells and Follicular Fluid of Polycystic Ovary Syndrome Associating with Different Phenotypes. Sci Rep 2017;7:14671.
35. Naji M, Nekoonam S, Aleyasin A, et al. Expression of miR-15a, miR-145, and miR-182 in granulosalutein cells, follicular fluid, and serum of women with polycystic ovary syndrome (PCOS). Arch Gynecol Obstet 2018;297:221-31.

36. Butler AE, Ramachandran V, Hayat S, et al. Expression of microRNA in follicular fluid in women with and without PCOS. Sci Rep 2019;9:16306.

37. Li X, Zhang W, Fu J, et al. MicroRNA-451 is downregulated in the follicular fluid of women with endometriosis and influences mouse and human embryonic potential. Reprod Biol Endocrinol 2019;17:96.

38. Richards JS, Russell DL, Ochsner S, et al. Novel signaling pathways that control ovarian follicular development, ovulation, and luteinization. Recent Prog Horm Res 2002;57:195-220.

39. Conti M, Hsieh M, Zamah AM, et al. Novel signaling mechanisms in the ovary during oocyte maturation and ovulation. Mol Cell Endocrinol 2012;356:65-73.

40. Li Y, Xiang Y, Song Y, et al. Dysregulated miR-142, -33b and -423 in granulosa cells target TGFBR1 and SMAD7: a possible role in polycystic ovary syndrome. Mol Hum Reprod 2019;25:638-46.

41. Luo H, Han Y, Liu J, et al. Identification of microRNAs in granulosa cells from patients with different levels of ovarian reserve function and the potential regulatory function of miR-23a in granulosa cell apoptosis. Gene 2019;686:250-60.

42. Sirotkin AV, Lauková $M$, Ovcharenko D, et al. Identification of microRNAs controlling human ovarian cell proliferation and apoptosis. J Cell Physiol 2010;223:49-56.

43. Jiang L, Huang J, Li L, et al. MicroRNA-93 promotes ovarian granulosa cells proliferation through targeting CDKN1A in polycystic ovarian syndrome. J Clin Endocrinol Metab 2015;100:E729-38.

44. Roth LW, McCallie B, Alvero R, et al. Altered microRNA and gene expression in the follicular fluid of women with polycystic ovary syndrome. J Assist Reprod Genet 2014;31:355-62.

45. Fiedler SD, Carletti MZ, Hong X, et al. Hormonal regulation of MicroRNA expression in periovulatory mouse mural granulosa cells. Biol Reprod 2008;79:1030-7.

46. Yin M, Lü M, Yao G, et al. Transactivation of microRNA- 383 by steroidogenic factor- 1 promotes estradiol release from mouse ovarian granulosa cells by targeting RBMS1. Mol Endocrinol 2012;26:1129-43.

47. Yao G, Liang M, Liang N, et al. MicroRNA-224 is 
involved in the regulation of mouse cumulus expansion by targeting Ptx3. Mol Cell Endocrinol 2014;382:244-53.

48. Long W, Zhao C, Ji C, et al. Characterization of serum microRNAs profile of PCOS and identification of novel non-invasive biomarkers. Cell Physiol Biochem 2014;33:1304-15.

49. Montazerian M, Yasari F, Aghaalikhani N. Ovarian extracellular MicroRNAs as the potential noninvasive biomarkers: An update. Biomed Pharmacother 2018;106:1633-40.

50. Imbar T, Eisenberg I. Regulatory role of microRNAs in ovarian function. Fertil Steril 2014;101:1524-30.

51. Zhang B, Chen L, Feng G, et al. MicroRNA Mediating Networks in Granulosa Cells Associated with Ovarian Follicular Development. Biomed Res Int 2017;2017:4585213.

52. Ding CF, Chen WQ, Zhu YT, et al. Circulating microRNAs in patients with polycystic ovary syndrome. Hum Fertil (Camb) 2015;18:22-9.

53. Machtinger R, Rodosthenous RS, Adir M, et al. Extracellular microRNAs in follicular fluid and their potential association with oocyte fertilization and embryo quality: an exploratory study. J Assist Reprod Genet

doi: 10.21037/exrna-20-3

Cite this article as: Wang Z, Zhang Y, Yang A, Ren Y, Zhang Q, Wang P. Extracellular microRNAs in follicular fluids: implication for reproductive diseases. ExRNA 2021;3:4.
2017;34:525-33.

54. Etheridge A, Lee I, Hood L, et al. Extracellular microRNA: a new source of biomarkers. Mutat Res 2011;717:85-90.

55. Harwood BN, Cross SK, Radford EE, et al. Members of the WNT signaling pathways are widely expressed in mouse ovaries, oocytes, and cleavage stage embryos. Dev Dyn 2008;237:1099-111.

56. Zheng P, Vassena R, Latham K. Expression and downregulation of WNT signaling pathway genes in rhesus monkey oocytes and embryos. Mol Reprod Dev 2006;73:667-77.

57. Boyer A, Goff AK, Boerboom D. WNT signaling in ovarian follicle biology and tumorigenesis. Trends Endocrinol Metab 2010;21:25-32.

58. Dang Y, Zhao S, Qin Y, et al. MicroRNA-22-3p is downregulated in the plasma of Han Chinese patients with premature ovarian failure. Fertil Steril 2015;103:802-7.e1.

59. Zhu T, Gao W, Chen X, et al. A Pilot Study of Circulating MicroRNA-125b as a Diagnostic and Prognostic Biomarker for Epithelial Ovarian Cancer. Int J Gynecol Cancer 2017;27:3-10. 